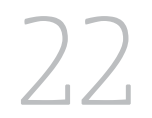

\title{
HEALTH CO-BENEFITS OF CLIMATE CHANGE MITIGATION POLICIES
}

\author{
ANDY HAINES
}

\begin{abstract}
Policies to reduce greenhouse gas emissions in a number of sectors can result in ancillary (co-benefits) for health. In the case of electricity generation, for example, reduced combustion of coal would result in lowered fine particulate air pollution. Improved housing insulation with efficient ventilation systems can reduce indoor air pollution while also reducing exposure to heat and cold extremes. In low-income settings, improved efficiency cookstoves can reduce black carbon emissions and other climate-active pollutants while reducing exposure to hazardous indoor air pollution. Urban transport policies that support active travel and access to affordable public transport can increase physical activity and reduce air pollution. Increased fruit and vegetable consumption and reduced consumption of animal products (particularly from ruminants) in highconsuming populations can improve health and reduce greenhouse gas (GHG) emissions. Finally, addressing reproductive health rights in countries where the need for modern contraception is not fully met can improve the prospects for child and maternal survival and ultimately reduce GHG emissions. Taking into account the value of the health gains and other co-benefits of policies to mitigate climate change can help to offset the costs of such policies and make them more acceptable to decision makers.
\end{abstract}

\section{Background}

Current trends of inequitable and unsustainable development, which are largely responsible for many of the environmental threats now confronting us, are related directly or indirectly to many risk factors responsible for major causes of ill health, particularly non-communicable diseases (NCDs). These now account for over half of the world's disease burden. This chapter illustrates 
linkages between health and policies in a number of sectors responsible for large emissions of greenhouse gases (GHG) or short-lived, climate-active pollutants such as black carbon. It also makes the case that appropriately designed policies to reduce emissions, and thus mitigate climate change, can improve health in the near term, over and above the improvements from reducing the probability of dangerous climate change. First, as this book is for a Festschrift, I document the early years of my collaboration with Tony McMichael.

\section{My Collaboration with Tony McMichael}

As mentioned in the introduction of this volume (Chapter 1), Tony had left the London School of Hygiene and Tropical Medicine by the time I was appointed Dean in December 2000. However, I was well aware of Tony's work and influence in relation to climate change and health. We had collaborated extensively on these issues since 1993, first in a paper (part of a pioneering special series in The Lancet on global change and health) that we wrote with the late Paul Epstein (Haines et al., 1993). Later, we contributed to the second and third Intergovernmental Panel on Climate Change (IPCC) reports, which were the first to include chapters on health, each of which was led by McMichael (McMichael et al., 1996; McMichael et al., 2001).

Tony and I also co-edited (including with Sari Kovats) the first book to assemble systematically the evidence on climate change and health (McMichael et al., 1996) and wrote several other co-authored papers on climate and health from the late 1990s (Haines and McMichael, 1997; McMichael and Haines, 1997; Haines et al., 2000). Tony's wide influence extended well beyond climate change, of course, as this book illustrates.

\section{Electricity Generation}

The combustion of fossil fuels for electricity generation, particularly coal, is responsible for a substantial proportion of air pollution due to fine particulates, notably in countries such as India and China. In general, as societies develop, exposure of populations to outdoor air pollution rises at first, then decreases as more effective particulate pollution controls are implemented and other sources of energy or more efficient technologies are used, particularly for electricity generation and transportation. This phenomenon is well illustrated in the case of London, the original 'Big Smoke', as exemplified by the Great Smog of 1952 (Bell et al., 2004) and subsequent clean air legislation. However, there is increasing appreciation that the switch to alternative means of power generation (and more efficient vehicles) does not fully address the challenge of 
fine particulate air pollution, which remains at unacceptably high levels today, even in many high-income countries, with the accompaniment of large, and in some cases increasing, emissions of greenhouse gases.

Overall, currently, exposure to ambient (outdoor) particulate matter is estimated to be responsible for around 3.2 million premature deaths per year worldwide (Lim et al., 2012). Recent World Health Organization (WHO) estimates (WHO, 2014a) suggest the burden may be even higher, at around 3.7 million premature deaths.

\section{Household Environment}

Additionally, in low-income countries, exposure to high levels of household air pollution due to inefficient combustion of solid fuels - biomass or coal - is responsible for major contributions to the burden of disease (e.g. lower respiratory tract infections, chronic obstructive pulmonary disease and ischaemic heart disease (IHD)), and is also associated with substantial emissions of short-lived climate pollutants such as black carbon. Overall, household air pollution is estimated to be responsible for around 3.5 million premature deaths per year (Lim et al., 2012), or even higher according to recent WHO estimates of 4.3 million per annum (WHO, 2014b), with some overlap between both categories as household sources contribute to ambient exposure, particularly in urban settings.

In high- and middle-income countries, the household environment can contribute to ill health in various ways, including mould and damp, indoor air pollutants such as radon and environmental tobacco smoke, and exposure to cold and/or heat (Wilkinson et al., 2009). Household environments can also pose fire risks at all levels of development, but particularly where open fires are used. Poor design and maintenance has resulted in the construction of many dwellings that use energy inefficiently because of heat loss (or gain) due to inadequate insulation and/or ventilation control. This can contribute to uncomfortable or harmful indoor temperatures, fuel poverty and the emission of large amounts of GHGs, where the energy source is from the combustion of fossil fuels.

\section{Food and Agriculture}

The agriculture sector is responsible for 10-12 per cent of global GHG emissions (an additional 6-17 per cent if land-use change is included). Of the non-land-use emissions from this sector, around 80 per cent are due to livestock, particularly as the result of methane emissions from ruminants such as cows and sheep 
(Steinfeld et al., 2006). The demand for animal products is increasing as populations become more affluent, and is driving forest clearance in some parts of the world. At a time when freshwater supplies are diminishing in many regions, animal products also contain large amounts of embedded water.

The global food production system is focused increasingly on promoting the consumption of refined, energy-dense food containing substantial amounts of saturated fats from animal sources and refined carbohydrates. At the same time, recent estimates suggest that inadequate consumption of fruit and vegetables is responsible for large burdens of disease such as some types of cancer and IHD (Lim et al., 2012). Replacing some animal source saturated fat by increased dietary intake of unsaturated fats (largely from liquid vegetable oils) can also reduce IHD risk (Hooper et al., 2011). Consumption of red and processed meat is associated with increased risk of colon and rectal cancer, diabetes and, in the case of the latter, IHD.

\section{Urban Transport}

Around 3.2 million premature deaths a year are thought to be related to physical inactivity (Lim et al., 2012), partly because of the growth in motorised transport, particularly private cars. Low levels of physical activity have been found consistently to increase the risk of seven conditions - diabetes, IHD, cerebrovascular disease, breast and large bowel cancer, Alzheimer's disease and depression (Woodcock et al., 2009). Road transport is responsible for a growing proportion of GHG emissions, as well as contributing substantially to urban air pollution, particularly due to fine particulates from diesel engines. Road injuries are responsible for nearly 1.3 million deaths a year, particularly of pedestrians and cyclists.

\section{Addressing Reproductive Health Needs}

Reducing population growth can bring direct and indirect benefits to health and to the environment through improved child survival and reduced maternal mortality, and by alleviating pressures on land use. In low-income countries, this will have limited effects on GHG emissions in the near term, but it could have substantial effects in the long term, particularly if poor populations adopt Western lifestyles in large numbers ( $\mathrm{O}^{\prime} \mathrm{Neill}$ et al., 2012). Population growth has slowed in many parts of the world but remains high in parts of sub-Saharan Africa, with projections suggesting a world population of around 10 billion before the end of this century. The unmet need for contraception is as high as 30 per cent in some sub-Saharan African countries. Funding for family planning 
on a per capita basis has fallen over the last decade in virtually all recipient nations. Population growth in high resource use economies could also have an important impact on future GHG emissions. For example, the population of the USA will rise from just over 300 million in 2010 to up to 458 million in 2050, depending on migration levels (Ortman and Guarneri).

\section{Measuring Progress Towards Sustainable Development Using Indicators that Link Health with Development Policies}

Access to information about sector policies and their associated health risks and impacts through the integrated indicators of health, development and environment and through the systematic health impact assessment of policies is key to improving global governance for sustainable development, as well as to raising public awareness and the accountability of decision makers. It will be critical to take such an approach when considering the Sustainable Development Goals that will come into operation following the Millennium Development Goals (MDGs), which are supposed to be achieved by the end of 2015. These goals and their associated indicators might include, for example, levels of ambient particulate air pollution and access to clean sources of household energy, the proportion of journeys by public transport and active travel in cities, consumption of diets that are both healthy and low in GHG emissions (Dora et al., 2015).

\section{Co-benefits to Health of Environmentally Sustainable Policies in Different Sectors}

It is increasingly recognised that there are health co-benefits (i.e. ancillary benefits) from policies to reduce GHG emissions (Haines et al., 2009). These health co-benefits can reduce the costs to health-care systems and can increase labour productivity. The economic benefits arising from health co-benefits can partly or wholly offset the costs of implementing low greenhouse gas emission strategies, depending on the sector, the assumptions made and the socio-economic context (Jensen et al., 2013).

Some low GHG emission technologies may, however, have adverse health effects; for example, the growth of biofuels that compete for land for food crops may increase food prices (FAO, 2013), and the emission reductions from some types of biofuels (e.g. maize alcohol) have been challenged. Excessively 'tight' buildings can increase indoor air pollution. Overall, however, health can be improved 
through more efficient use of energy in housing, with benefits exceeding the costs of insulation, provided adequate ventilation is maintained (Wilkinson et al., 2009). Each potential GHG mitigation strategy should be assessed on a caseby-case basis.

In developing countries, new stove technologies can reduce indoor air pollution, and lower fuel consumption as well as the risk of acute respiratory infections in children, chronic obstructive pulmonary disease and IHD (Wilkinson et al., 2009). More efficient stoves save time needed for cooking and time and energy collecting wood, and thus also lower the risk of violence, particularly against women for whom collecting fuel is a potential risk.

Transportation policies have a great potential to prevent NCDs, especially in rapidly growing cities that face large increases in motor vehicles. Greater reliance on public transport systems and walking and cycling reduces air pollution and noise, promotes physical activity and can potentially lessen traffic injuries. These policies also give access to goods and services to the poor and to women, children and the elderly, who rarely own a private vehicle. Longitudinal studies show that people in Copenhagen (Andersen et al., 2000) and Shanghai (Matthews et al., 2007) who cycle to work regularly have 30 per cent lower all-cause mortality than those who do not. Transport interventions and urban planning are among the most effective interventions to promote physical activity.

Shifting away from the combustion of coal for electricity generation will reduce GHG emissions and deaths associated with fine particulate air pollution, particularly in developing countries (Markandya et al., 2009).

Shindell and colleagues (2012) identified 14 measures targeting methane and black carbon emissions that would reduce projected global mean warming $\sim 0.5^{\circ} \mathrm{C}$ by 2050 . These strategies would avoid $0.7-4.7$ million annual premature deaths from outdoor air pollution and improve agricultural productivity. The estimated value of the benefits significantly exceeded the typical marginal abatement costs.

Increasing the consumption of fruit, vegetables and unsaturated fat, together with reducing animal product consumption (particularly from ruminants) in high-consuming countries, could benefit health and reduce greenhouse gas emissions (McMichael et al., 2007; Friel et al., 2009), as well the pressure on land for growing animal feed stocks. 
Stern (2010) has suggested that the cost of holding concentrations of GHGs below 500 parts per million $\mathrm{CO}_{2} \mathrm{e}^{1}$ are around 2 per cent of global gross domestic product (GDP), but could be considerably less if technological progress was rapid. According to his analysis, the benefits of early action as a result of averting some of the adverse effects of climate change on the world economy outweigh the costs. The health and other co-benefits of these policies, which will in many cases be felt in the relatively near term, provide an added incentive for their implementation.

Currently, energy subsidies for fossil fuels amount to US $\$ 1.9$ trillion (2.5 per cent of global GDP) on a post-tax basis - which also factors in the negative externalities from energy consumption. Removing these subsidies would lead to an estimated 13 per cent reduction in $\mathrm{CO}_{2}$ emissions and reduce inequalities (International Monetary Fund, 2013).

With new and emerging 'clean' technologies, increased energy efficiency and the implementation of policies to reduce inequities and promote healthier lifestyles, there is the potential for greatly improved health worldwide at much lower levels of environmental impact than today.

\section{References}

Andersen, L.B., Schnohr, P., Schroll, M. \& Hein, H.O. 2000. All-cause mortality associated with physical activity during leisure time, work, sports, and cycling to work. Archives of Internal Medicine 160, 1621-8.

Bell, M.L., Davis, D.L. \& Fletcher, A. 2004. A retrospective assessment of mortality from the London smog episode of 1952; the role of influenza and pollution. Environmental Health Perspectives 112, 6-8.

Dora, C., Haines, A., Balbus, J., Fletcher, E., Adair-Rohani, H., et al. 2015. Indicators linking health and sustainability in the post 2015 development agenda. The Lancet 385, 380-91.

FAO 2013. Biofuels and food security. A Report by a High Level Panel of Experts on Food Security and Nutrition June 2013. Available at: www.fao. org/fileadmin/user_upload/hlpe/hlpe_documents/HLPE_Reports/HLPEReport-5_Biofuels_and_food_security.pdf, accessed 23 March 2014.

$1 \mathrm{CO}_{2}$ equivalent $\left(\mathrm{CO}_{2} \mathrm{e}\right)$ is an aggregate measure of the main GHGs (e.g. $\mathrm{CO}_{2}$ and methane) in $\mathrm{CO}_{2} \mathrm{e}$ 'units', which reflects their global warming potential over a given period. The concept has limitations, for example, because of the wide range of residence times in the atmosphere of different GHGs and short-lived climate pollutants, but is nevertheless widely used. 
Friel, S., Dangour, A.D., Garnett, T., Lock, K., Chalabi, Z., Roberts, I., et al. 2009. Public health benefits of strategies to reduce greenhouse-gas emissions: food and agriculture. The Lancet 374, 2016-25.

Haines, A. \& McMichael, A.J. 1997. Climate change and health: implications for research, monitoring, and policy. BMJ 315, 870-4.

Haines, A., Epstein, P.R. \& McMichael, A.J. 1993. Global health watch: monitoring impacts of environmental change. The Lancet 342, 1464-9.

Haines, A., McMichael, A.J. \& Epstein, P.R. 2000. Global climate change and health. Canadian Medical Association Journal 163, 729-34.

Haines, A., McMichael, A.J., Smith, K.R., Roberts, I., Woodcock, J., Markandya, A., et al. 2009. Public health effects of strategies to reduce greenhousegas emissions: overview and implications for policy makers. The Lancet 374, 2104-14.

Hooper, L., Summerbell, C.D., Higgins, J.P.T., Thompson, R.L., Clements, G., Capps, N., et al. 2011. Reduced or modified dietary fat for preventing cardiovascular disease. The Cochrane Database of Systematic Reviews 7, CD002137.

International Monetary Fund. 2013. Energy Subsidy Reform: Lessons and Implications. January 2013. Available at: www.imf.org/external/np/pp/ eng/2013/012813.pdf, accessed 23 March 2014.

Jensen, H., Keogh-Brown, M., Smith, R., Chalabi, Z., Dangour, A., Davies, M., et al. 2013. The importance of health co-benefits in macroeconomic assessments of UK greenhouse gas emission reduction strategies. Climatic Change 121, 223-37.

Lim, S.S., Vos, T., Flaxman, A.D., Danaei, G., Shibuya, K., Adair-Rohani, H., et al. 2012. A comparative risk assessment of burden of disease and injury attributable to 67 risk factors and risk factor clusters in 21 regions, 19902010: a systematic analysis for the Global Burden of Disease Study 2010. The Lancet 380, 2224-60.

McMichael, A.J. \& Haines, A. 1997. Global climate change: the potential effects on health. BMJ 315, 805-9.

McMichael, A.J., Ando, M., Carcavallo, R., Epstein, P., Haines, A., Jendritzky, G., et al. 1996. Human population health. In: Watson, R.T., Zinyowera, M.C. \& Moss, R.H. (eds) Climate Change 1995, Impacts, Adaptations and Mitigation of Climate Change: Scientific Technical Analyses. Contribution of 
Working Group II to the Second Assessment Report of the Intergovernmental Panel on Climate Change. Cambridge University Press, Cambridge, UK, New York USA, 561-84.

McMichael, A.J., Haines, A., Slooff, R. \& Kovats, S. (eds) 1996. Climate Change and Human Health. World Health Organization, Geneva, Switzerland.

McMichael, A.J., Githeko, A., Akhtar, R., Carcavallo, R., Gubler, D., Haines, A., et al. 2001. Human health. In: McCarthy, J., Canziani, O.F., Leary, N., Dokken, D.J. \& White, K.S. (eds) Climate Change 2001; Impact, Adaptation and Vulnerability. Contribution of Working Group II to the Third Assessment Report of the Intergovernmental Panel on Climate Change. Intergovernmental Panel on Climate Change, Cambridge, UK, New York USA, 451-86.

McMichael, A.J., Powles, J., Butler, C.D. \& Uauy, R. 2007. Food, livestock production, energy, climate change and health. The Lancet 370, 1253-63.

Markandya, A., Armstrong, B.G., Hales, S., Chiabai, A., Criqui, P., Mima, S., et al. 2009. Public health benefits of strategies to reduce greenhouse-gas emissions: low-carbon electricity generation. The Lancet 374, 2006-15.

Matthews, C.E., Jurj, A.L., Shu, X.-O., Li, H.-L., Yang, G., Li, Q., et al. 2007. Influence of exercise, walking, cycling, and overall non-exercise physical activity on mortality in Chinese women. American Journal of Epidemiology $165,1343-50$.

O'Neill, B.C., Liddle, B., Jiang, L., Smith, K.R., Pachauri, S., Dalton, M., et al. 2012. Demographic change and greenhouse gas emissions. The Lancet 380, $157-64$.

Ortman, J.M. \& Guarneri, C.E. United States Population Projections 2000-2050. Available at: www.census.gov/population/projections/files/analyticaldocument09.pdf, accessed 21 March 2014. CD002137.

Shindell, D., Kuylenstierna, J.C.I., Vignati, E., van Dingenen, R., Amann, M., Klimont, Z., et al. 2012. Simultaneously mitigating near-term climate change and improving human health and food security. Science 335, 183-8.

Steinfeld, H., Gerber, P., Wassenaar, T., Castel, V., Rosales, M. \& de Haan, C. 2006. Livestock's Long Shadow. FAO, Rome, Italy.

Stern, N.A. 2010. Blueprint for a Safer Planet. Vintage Books, London, UK.

WHO 2014a. Ambient (outdoor) air quality and health. Fact sheet No 313, updated March 2014. World Health Organization, Geneva, Switzerland. Available at: www.who.int/mediacentre/factsheets/fs313/en, accessed 15 April 2014. 
WHO 2014b. Household air pollution and health 2014. Fact sheet No 292, updated March 2014. World Health Organization, Geneva, Switzerland. Available at: www.who.int/mediacentre/factsheets/fs292/en, accessed 15 April 2014.

Wilkinson, P., Smith, K.R., Davies, M., Adair, H., Armstrong, B.G., Barrett, M., et al. 2009. Public health benefits of strategies to reduce greenhouse-gas emissions: household energy. The Lancet 374, 1917-29.

Woodcock, J., Edwards, P., Tonne, C., Armstrong, B.G., Ashiru, O., Banister, D., et al. 2009. Public health benefits of strategies to reduce greenhouse-gas emissions: urban land transport. The Lancet 374, 1930-43. 
This text is taken from Health of People, Places And Planet:

Reflections based on Tony McMichael's four decades of contribution to epidemiological understanding, edited by Colin D. Butler, Jane Dixon and Anthony G. Capon, published 2015 by ANU Press, The Australian National University, Canberra, Australia. 